\title{
Postmenopausal breast cancer: European challenge and innovative concepts
}

\author{
Ivica Smokovski $^{1,2}$ - Milan Risteski ${ }^{3}$. Jiri Polivka Jr ${ }^{4,5}$ • Pavol Zubor ${ }^{6,7}$. \\ Katarzyna Konieczka $^{8}$ - Vincenzo Costigliola ${ }^{9}$ - Olga Golubnitschaja ${ }^{10,11,12}$
}

Received: 4 April 2017 / Accepted: 29 April 2017 / Published online: 30 May 2017

(C) European Association for Predictive, Preventive and Personalised Medicine (EPMA) 2017

\begin{abstract}
Breast cancer (BC) epidemic is recognised now worldwide as the reality of the early twenty-first century. Increasing trends in the postmenopausal $\mathrm{BC}$ prevalence, even for the European countries earlier demonstrating relatively stable incidence rates of the disease, are highly alarming for the healthcare givers. This new actuality requires a substantial revision of the paradigm currently applied to the $\mathrm{BC}$ management and creation of highly innovative concepts. Current multi-centred study highlights new complex mechanisms of the development and progression of the postmenopausal BC. Innovative concepts are presented which argue for more effective predictive and preventive approaches well justified in view of the clusters of the symptoms analysed here and demonstrated as highly prevalent in the postmenopausal breast cancer versus BC-free individuals. Another conceptual novelty presented here is a new interpretation of the "Seed and Soil" theory of metastasis in BC. According to the new concept, the "pre-metastatic niches" ("Soil") are created by a systemic
\end{abstract}

Olga Golubnitschaja

olga.golubnitschaja@ukbonn.de

1 Faculty of Medical Sciences, University Goce Delcev Stip, Stip, Macedonia

2 Diabetes and Metabolic Disorders, University Clinic of Endocrinology, Skopje, Macedonia

3 University Clinic of Radiotherapy and Oncology, Skopje, Macedonia

4 Department of Histology and Embryology and Biomedical Centre, Faculty of Medicine in Plzen, Charles University, Prague, Czech Republic

5 Department of Neurology, Faculty Hospital Plzen, Plzen, Czech Republic hypoxia a long time before the breast malignancy is clinically manifested.

Keywords Predictive preventive and personalised medicine . Postmenopausal breast cancer · Metastatic disease - "Seed and soil" theory · Risk factors · Diabetes · Flammer syndrome · Systemic hypoxia $\cdot$ Patient stratification $\cdot$ Cardiovascular component $\cdot$ Pain $\cdot$ Drug sensitivity

\section{Introduction}

Postmenopausal breast cancer as the European challenge

Breast cancer (BC) epidemic is recognised now worldwide as the reality of the early twenty-first century [1]. Moreover, in the Eastern and Central European countries, amongst the four most common cancers, specifically the postmenopausal breast Medicine, Martin University Hospital, Martin, Slovak Republic

7 Division of Oncology, Biomedical Centre Martin, Jessenius Faculty of Medicine, Comenius University in Bratislava, Bratislava, Slovak Republic

8 Department of Ophthalmology, University of Basel, Basel, Switzerland

9 European Medical Association, EMA, Brussels, Belgium

10 Radiological clinic, Rheinische Friedrich-Wilhelms-University of Bonn, Sigmund-Freud-Str 25, 53105 Bonn, Germany

11 Breast Cancer Research Centre, Rheinische Friedrich-Wilhelms-University of Bonn, Bonn, Germany

12 Centre for Integrated Oncology, Cologne-Bonn, Rheinische Friedrich-Wilhelms-University of Bonn, Bonn, Germany 
cancer started to approach the incidence levels earlier registered for the Northern and Western Europe, where their rates traditionally were the highest ones within the European area [2]. Increasing trends in the postmenopausal breast cancer prevalence, even for the European countries earlier demonstrating relatively stable incidence rates of the disease, are highly alarming for the healthcare givers. This new actuality requires a substantial revision of the paradigm currently applied to the breast cancer management and creation of highly innovative concepts, first of all, for the primary prevention of breast cancer.

\section{New concepts}

By a series of recently published articles, we have introduced highly promising concepts which strongly support the recognition of the breast cancer pathology as the systemic disorder and suggest innovative solutions in the context of predictive, preventive and personalised medicine [3-5]. Herewith, we briefly summarise the facts and findings which have motivated the current study.

\section{Feeling cold and disturbed thermoregulation in BC pathology}

Compared to the general population, $\mathrm{BC}$ patients complain more frequently about deficits in achieving thermal comfort $[3,4]$. They feel excessively hot or cold even in situations when disease-free attendees are well comfortable with ambient temperature conditions [6]. The prevalence of both symptoms "Feeling inadequately cold" and "Cold extremities" has been demonstrated in breast cancer and metastatic disease versus breast cancer-free individuals $[4,5]$.

\section{Relevance of the cardiovascular component}

Panels of biomarkers and symptoms have been investigated demonstrating the cardiovascular component as being prominently relevant for the development, progression and individual outcomes of the BC pathology [4, 5, 7].

\section{Hypoxic effects and pre-metastatic niches}

By evidence, both initial tumours and secondary metastases need a "fertile" microenvironment effectively supporting their growth and progression [8]. Systemic hypoxic effects linked to the cardiovascular component create this fertile microenvironment playing the central role in progressive $\mathrm{BC}$ and metastatic disease $[3,9,10]$. Thereby, the appearance of the "premetastatic niches" may occur prior to the tumour onset resulting in the particularly aggressive metastatic disease developing at early stages of breast cancer [5].

\section{Altered sense regulation}

Panel of symptoms has been investigated indicating potentially altered sense regulation as a component of the $\mathrm{BC}$ pathology [4]. For example, underrepresented feeling of thirst may result in strong body dehydration and disturbed detoxification pathways, which in turn may cause significant toxic effects increasing $\mathrm{BC}$ risks [3].

\section{Drug sensitivity may be potentially altered in BC}

Drug sensitivity is the major issue for individual outcomes in treated BC. Potentially altered drug sensitivity in $\mathrm{BC}$ patients has been indicated $[4,5]$.

\section{Headache and $\mathrm{BC}$ risks}

Headache is a controversially discussed BC risk factor. We assume that a correct interpretation of the condition may depend on the context and pathology-specific biomarker panels to be applied [3-5].

\section{Psychological patterns}

Doubtlessly, psychological factors are important for the individual outcomes in BC [1]. However, this area is currently underdeveloped and clear patterns of the most relevant psychological factors have not yet been created for predictive and prognostic purposes in the overall breast cancer management.

\section{Closing the gaps}

In order to close the evident gaps in our current knowledge listed above, our current study investigates the prevalence of the individual symptoms of the "Flammer Syndrome" (FS) in the cohort of the postmenopausal breast cancer patients. FS phenotype [11] is described for both healthy individuals in sub-optimal health condition [12] and severely diseased patients [13]. FS is particularly relevant for females [11]. It is characterised by local and systemic hypoxic effects caused by vascular dysregulation [11] as well as molecular patterns which are evidently relevant for the $\mathrm{BC}$ cancer advancement [14-16] as described earlier.

\section{Materials and methods}

\section{Flammer syndrome diagnostic approach}

The Flammer syndrome (FS) phenotype has been characterised earlier [11]. The FS-related questionnaire utilised in the current study has been developed by the fielddedicated research group at the University Hospital Basel in 
Switzerland. The actual version of the FS-specialised questionnaire has been successfully applied to several international studies [17-22] and recently utilised for the multicentred pilot project focused on the breast cancer and metastatic disease $[4,5]$.

\section{Experimental design}

For this study, the patients have been recruited and interviewed by two specialised medical centres, the University Clinic of Oncology and Radiotherapy, Skopje, Republic of Macedonia, and Department of Obstetrics and Gynaecology, Jessenius Faculty of Medicine, Martin University Hospital, Martin, Slovak Republic. Both centres were involved in the international multi-centred study working in a tight collaboration with other European partners participating in the project. The reference group comprising breast cancer-free individuals (" $\mathrm{BC}$-free reference" patient cohort) has been created and interviewed by the Slovakian partner organisation. The cohort of postmenopausal breast cancer patients have been selected and interviewed in the Republic of Macedonia. The partner organisations of the international pilot project have elaborated both the "including" and "excluding" criteria for the study and followed the same norms of ethics in accordance with the ethical standards of the institutional and national research committees and with the international principles of the 1964 Helsinki declaration and its later amendments.

\section{Breast cancer-free reference cohort}

The patient data-base available at the Department of Obstetrics and Gynaecology, Jessenius Faculty of Medicine, Martin University Hospital, Martin, Slovak Republic, has been utilised for selecting the breast cancer-free individuals as potential responders. Altogether, 73 breast cancer-free individuals have been recruited for this study as reported in the original publication [4]. Following patient cohorts have been included:

- Healthy individuals free of breast cancer and any other malignancy (52 individuals of total)

- Benign breast fibro-adenoma (FIA), free of breast cancer and any other malignancy (21 patients of total).

\section{Selection and examination of healthy individuals}

Healthy individuals have been clinically examined attesting an absence of gynaecological problems and interviewed personally for the study during their hospital outpatient visit performed in the framework of the national screening programme. BC-free condition has been confirmed either by breast sonography or mammography or both imaging approaches. The examination reports used were not older than 6 months. Healthy individuals selected for this study demonstrated no history of any previously diagnosed breast pathology, no surgery performed due to breast lesions and no history of any severe gynaecologic disease including cancer other than breast malignancies or any systemic diseases such as diabetes mellitus, rheumatic diseases and neurological disorders. The entire methodological approach has been described in the original publication [4].

\section{Fibro-adenoma patients}

Imaging technologies have been applied for the first choice of the entire diagnostic procedure: digital mammography Hologic system, 2D + 3D sonography-Voluson USG system E8 and E10 machine, Birads 0-6 classification scoring system with double reading of the radiologic approach. In case of reasonable suspicion, the affected patients have undergone the biopsy analysis (either core needle or Mammotome's vacuumassisted). Histopathological analysis has, further, allowed for distinguishing between $\mathrm{BC}$ malignancy and fibro-adenoma (FIA) benignancy. FIA-individuals have been included into the $\mathrm{BC}$-free reference group of patients. The entire methodological approach has been described in the original publication [4].

\section{Breast cancer patient cohort}

Breast cancer patients with and without metastases, treated at the University Clinic of Oncology and Radiotherapy, Skopje, Republic of Macedonia, have been involved into the study. Patients have been selected utilising the data-base of the National eHealth System introduced in the Republic of Macedonia on July 1, 2013. This system fulfils all requirements of the international standards and covers studyrelevant information for all citizens of the Republic of Macedonia [23, 24]. Patients recruited for the current study have been identified as postmenopausal females with past history of menopause defined as one year after last menstrual period without bleeding, who have developed breast cancer after this time (in menopause), therefore, being postmenopausal breast cancer patients. These patients have been scheduled for visiting the University Clinic of Oncology and Radiotherapy in Skopje, Republic of Macedonia, during the period of time between September 20th and November 20th, 2016. Diagnosis and treatment of 67 selected breast cancer patients with and without metastatic disease have been performed in accordance with the National Guidelines for Medical Care of Breast Cancer [25]. These guidelines correspond to the international standards as stated in the governmental documents cited above. The meaning of individual questions of the FS questionnaire has been explained in extenso by the treating oncologist and/or oncologist's assistant during the communication with every interviewed patient. 
The questionnaire has been self-completed by the patients selected for the study.

\section{Statistical analysis}

For analytical and statistical evaluations, the data have been transferred to Microsoft Excel. SPSS Statistics v20.0.0 software (IBM, Armonk, NY, USA) has been applied. The prevalence of individual symptoms in groups of comparison has been evaluated and expressed in percentage. Pearson's chisquare test of associations has been applied. $P$ values below 0.05 have been considered as statistically significant.

\section{Results}

\section{General statistics}

Postmenopausal breast cancer patients (67 of total) demonstrated the age average of 59 years against 50 years for the reference group comprising BC-free individuals ( 73 of total). The age difference was evaluated as statistically non-significant. Postmenopausal breast cancer group demonstrated in average the BMI $=26$ (17-34). Fifty percent of this group were overweight persons and $20 \%$ were diagnosed with diabetes type 2 .

\section{FS prevalence evaluated by individual symptoms}

Figure 1 summarises the prevalence of individual Flammer syndrome symptoms (1-15) in two groups of comparison-the "Postmenopausal breast cancer" patients versus the reference group of "BC-free" individuals. Higher prevalence in postmenopausal breast cancer (red) has been demonstrated for altogether 11 symptoms. Statistically significant difference has been recorded for the symptoms 2 (feeling cold), 7 (headache), 9 (drug sensitivity), 11 (smell perception), and 12 (body weight in early adulthood); corresponding $P$ values are provided in Table 1 . In this study, breast cancer patients demonstrated higher body weight compared to the $\mathrm{BC}$-free reference group; the difference is statistically significant $(P=0.001)$. Although being statistically non-significant $(P=0.470)$, a substantially greater prevalence has been demonstrated for the symptom 6: "no feeling of thirst and drinking too little", the $\mathrm{BC}$ patients, in general, have demonstrated over two times more frequently compared to the disease-free reference group. Further, slightly higher prevalence in $\mathrm{BC}$ patient cohort has been demonstrated for the symptoms 1 (cold extremities), 3 (low blood pressure), 4 (dizziness), 5 (prolonged sleep onset), symptom 10 (pain), and symptom 15 (skin blotches in stress). Strong plurality has been demonstrated amongst BC patients for symptoms 8 (accompanying symptoms) and 10 (pain). Similar prevalence between $\mathrm{BC}$ patients and disease-free individuals has been demonstrated for the appearance of tinnitus
Fig. 1 Evaluation of the prevalence of individual symptoms (1-15) of the "Flammer Syndrome" phenotype in two groups of comparison: "Breast cancer diseased" (Postmenopausal BC) versus "Breast cancer free" reference patient pool (BC-free Ref). For more details regarding the patient recruitment and stratification - see "Materials and Methods". The prevalence in each individual group is presented by percentage of individuals who have responded to the corresponding question with "frequently" and "sometimes" pooled together. Responders answering with "I do not know" have been excluded from the overall numbers/ calculations. Question-specific notes: question 6-the ratio between "I do not feel thirsty and drink little" and "I feel much thirsty and drink a lot" has been calculated and expressed in $X$ times; question 12 - answers "very slim" and "slim" are pooled together and presented in percent

(symptom 14). Slightly decreased prevalence of the symptom 13 (perfectionism) has been demonstrated for BC patients. The results are summarised in Table 1.

\section{Discussion}

\section{Breast cancer screening in the Republic of Macedonia}

The breast screening campaign has been started in the Republic of Macedonia in 2007 involving 19 national mammography departments but has been criticised for only partially fulfilled requirements and standards settled for an effective breast cancer screening utilising mammographic approach [26]. Further, the field-dedicated professional groups in Macedonia systematically work on the risk prediction models for breast cancer providing clear arguments considering currently existing approaches as unsatisfactory in general and, therefore, leading to poor results and data interpretation [27]. Contextually, Macedonian national centres have been chosen for the current multicentred study as being highly motivated to develop innovative approaches in breast cancer screening, prediction and prevention at both - the national and European levels.

\section{Profile of the target patient group is typical for the postmenopausal breast cancer cohort}

The purpose of the current paper was to investigate a potential relevance of the Flammer Syndrome for a typical postmenopausal breast cancer patient cohort. Consequently, this is to emphasise that an averaged profile of the target patient group has been created which on mini-scale reflects the demographic and physiologic parameters ubiquitously recorded for the corresponding European patient cohorts, namely

- All postmenopausal breast cancer patients treated at the national medical centre in the Republic of Macedonia and involved in this study have been registered as the native Macedonian citizens

- The age of these patients ranged between 48 and 80 years old 

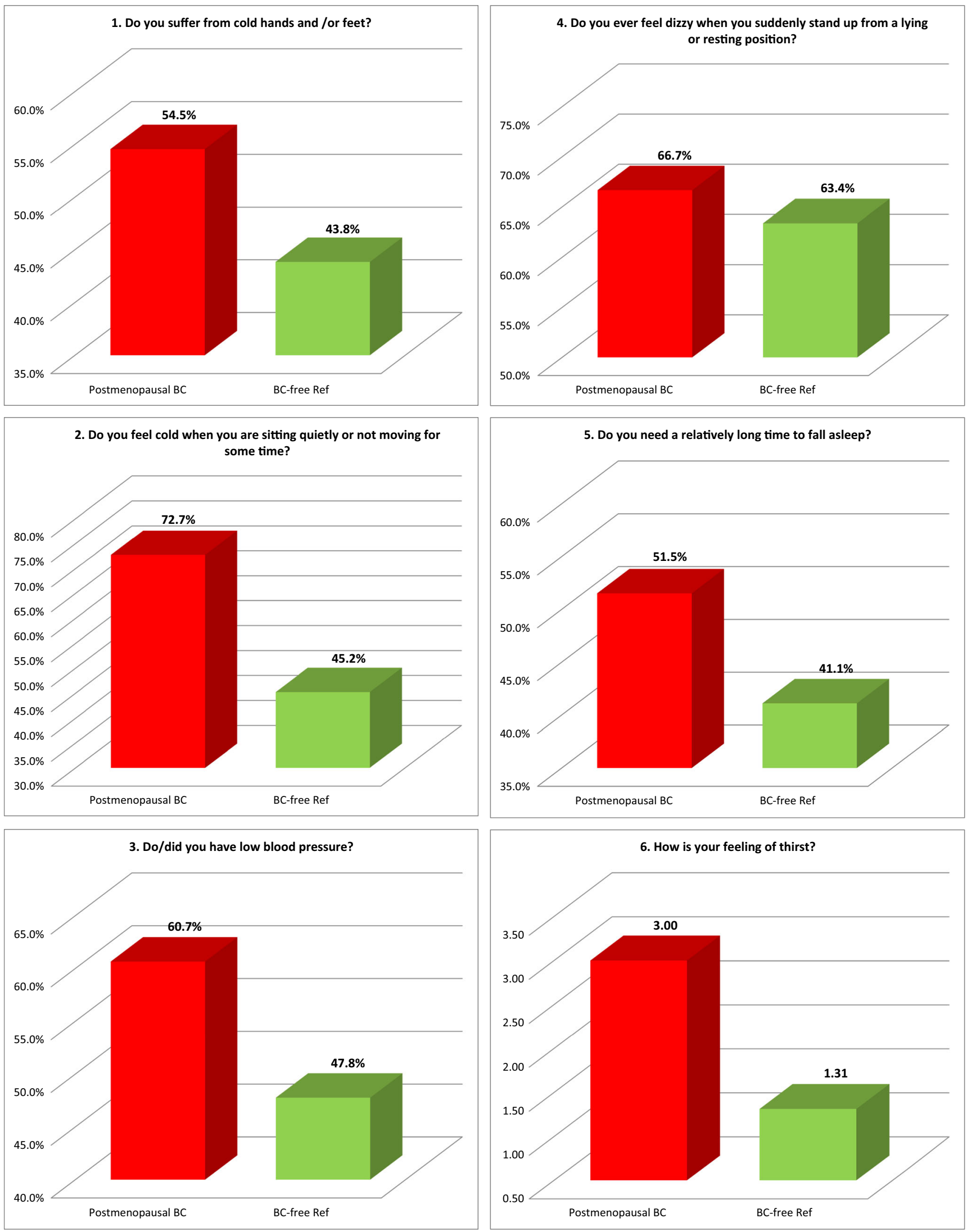

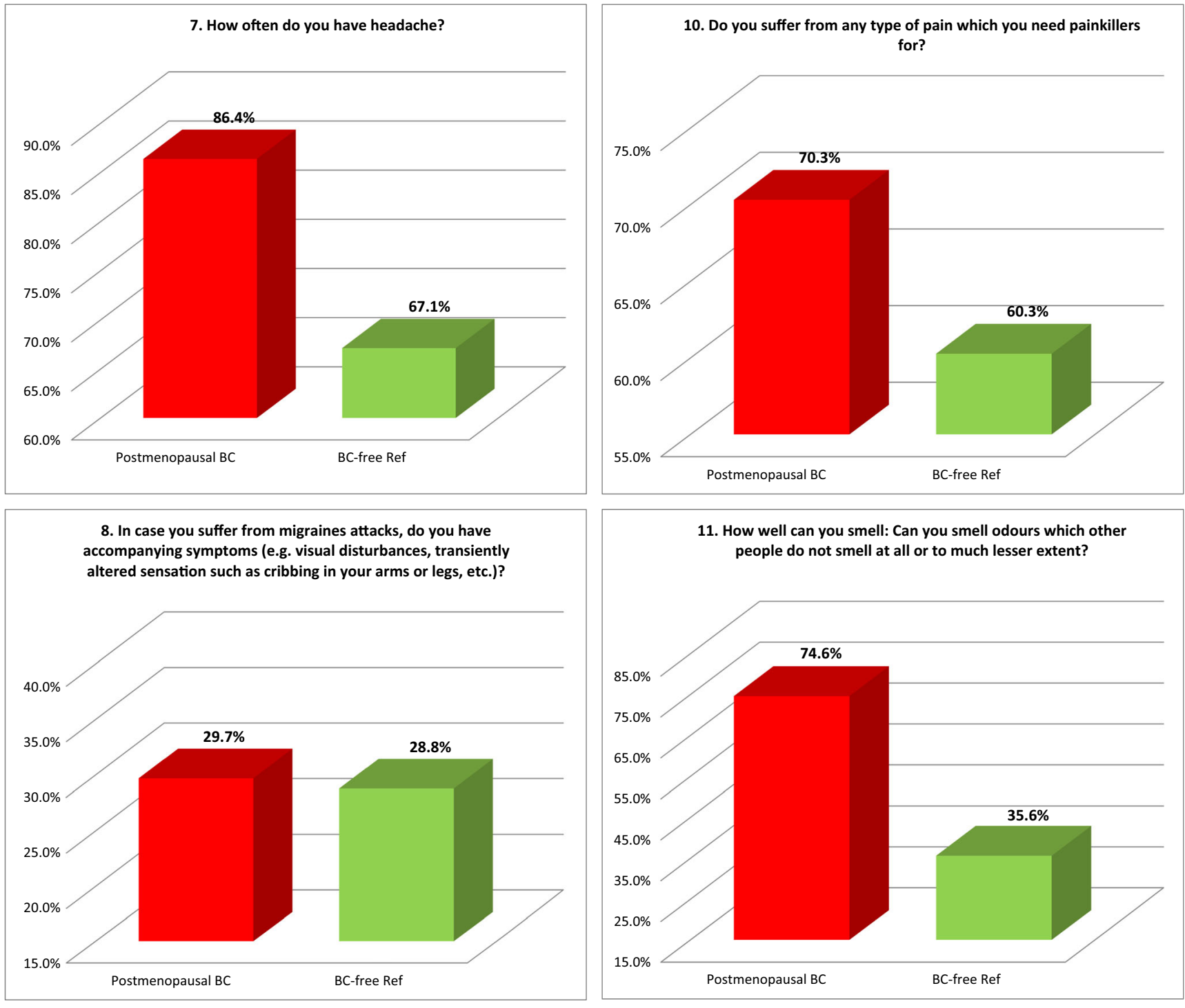

9. If you have to take medications (other than pain killers), do you have the feeling that you react very strongly to them and/or that you would feel better taking a lower dosis than that is usually

$$
\text { prescribed? }
$$
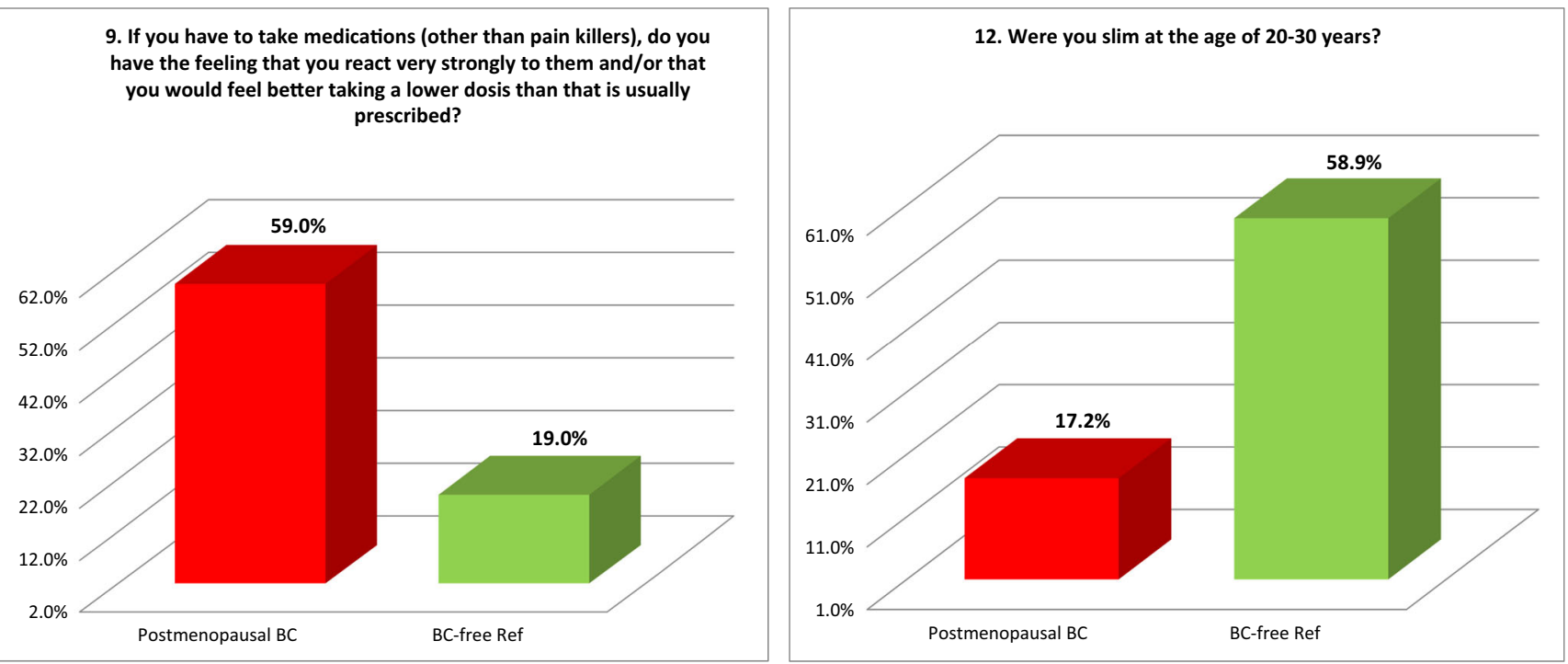

Fig. 1 continued. 


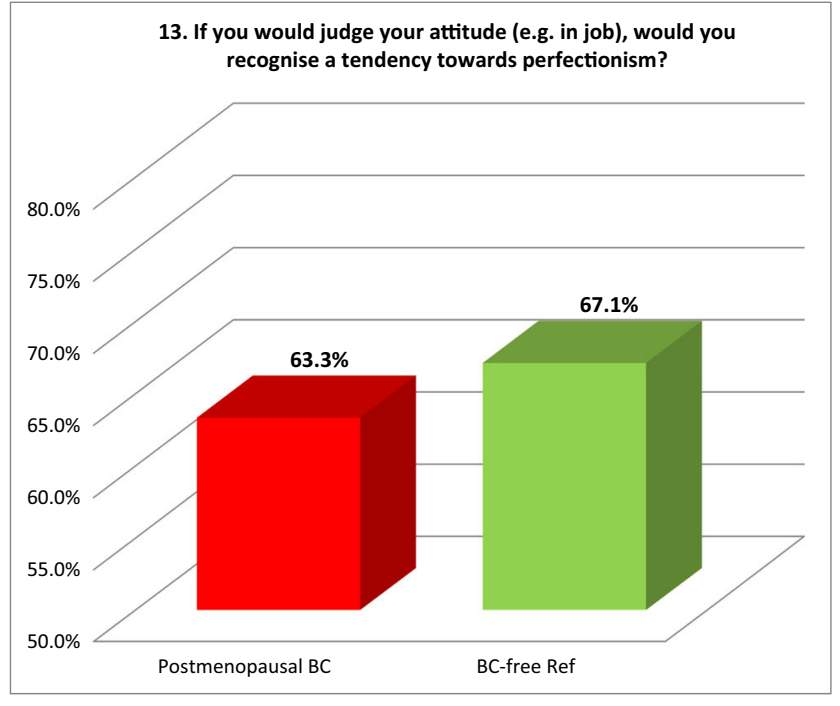

14. Do you notice ringing in your ears (tinnitus) from time to time?

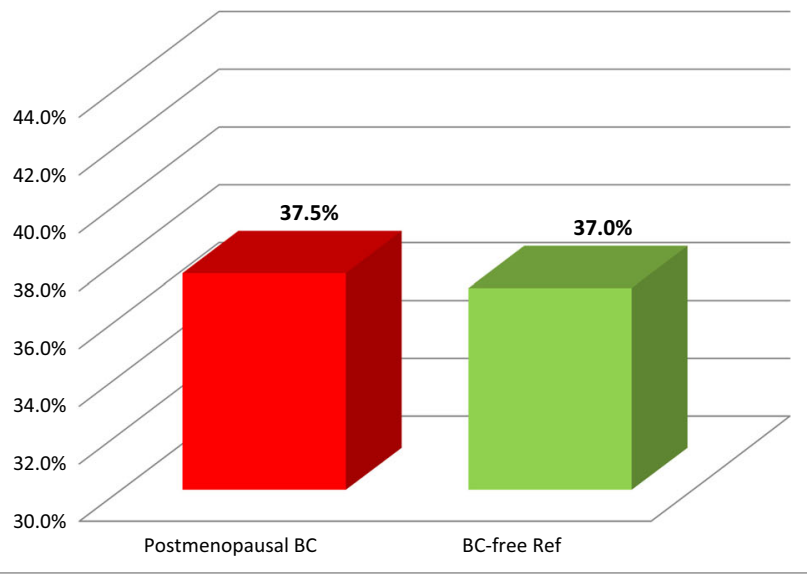

15. Have you noticed reversible blotches (white or red) on your skin when you were very excited or angry (e.g. in stress)?

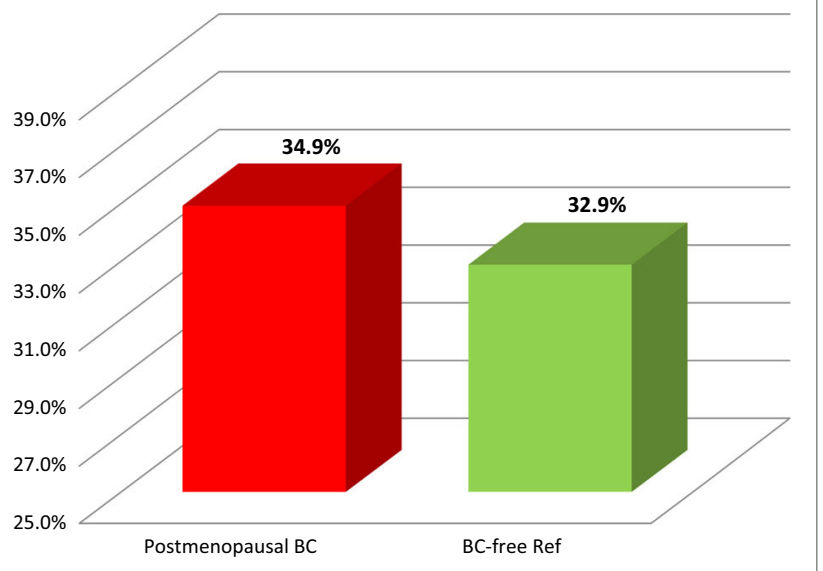

Fig. 1 continued.

- The low-weight persons created an absolute minorityaltogether, four patients with the $\mathrm{BMI} \leq 20$
- Fifty percent of all postmenopausal breast cancer patients were overweight persons characterised by the BMI ranging between 26 and 34

- Twenty percent of all postmenopausal breast cancer patients investigated in the current study have been diagnosed with diabetes type 2 .

- A big portion of this patient pool has been diagnosed with the metastatic breast cancer.

\section{Body shape and postmenopausal breast cancer risk}

In consensus with the results presented here, it has been clearly demonstrated that both in Europe and in the USA, women aged 60 and above are more likely to be overweight or obese than any other age groups [28, 29]. Overweight, obesity and diabetes mellitus type 2 are the risk factors well described in the context of the oestrogen-receptor-positive breast cancer prevalence specifically in postmenopausal women [30-33]. However, it does not explain the following facts. Firstly, far not all postmenopausal breast cancer patients are overweight, obese and or diagnosed with diabetes mellitus type 2 ; in the patient group investigated here, the averaged BMI was 26 and exactly $50 \%$ of patients overweight. Another $50 \%$ demonstrated normal body weight by $\mathrm{BMI} \leq 25$, however, being breast cancer diseased. Secondly, breast cancer is a chronic pathology developing over years or even decades of life. That means that the pre/cancer lesions were developing during premenopausal period of life, when the body weight was average. This seems to be the case in our study: about $90 \%$ of all respondents of the postmenopausal breast cancer group have noted that, although being not slim in contrast to the breast cancer-free reference group (the difference has been found significant, $P=0.001$ ), their body weight was within the normal range at the young age. Indeed, some recent studies demonstrate adverse effects of long-term adult weight gain for postmenopausal breast cancer [32]. This might justify the appearance of the postmenopausal breast cancer for about $50 \%$ of our target patient cohort. However, there is no currently provided explanation for another $50 \%$ of these patients from view point of risks by overweight, obesity and diabetes mellitus type 2 in elderly.

\section{What is new in the concepts presented here?}

The results presented in our current stud clearly demonstrate that postmenopausal breast cancer cannot be explained solely by appearance of individual risk factors such as increased BMI, fluctuating body weight and/or lifetime body size. It is a multi-factorial systemic disease with a great number of contributing factor which should be obligatory considered in the context of individual patient profiles for reliable prediction and prognosis. What is new in the concepts presented here? 
Table 1 Symptoms of the "Flammer Syndrome" recorded in "Postmenopausal breast cancer patients" versus "Breast cancer free individuals" groups of comparison; the table summarises the results demonstrated in Fig. 1; the following system is employed: "+" means higher prevalence of the corresponding symptom (above the lowest average of the groups of comparison); "-" means lower prevalence of the corresponding symptom (lowest average and below it)

\begin{tabular}{|c|c|c|c|c|}
\hline \multirow[t]{2}{*}{ Nr. } & \multirow{2}{*}{$\begin{array}{l}\text { "Flammer } \\
\text { Syndrome" } \\
\text { symptoms }\end{array}$} & \multicolumn{2}{|c|}{ Postmenopausal BC patients } & \multirow{2}{*}{$\begin{array}{c}\text { BC-free } \\
\text { individuals } \\
\text { Prevalence }\end{array}$} \\
\hline & & Prevalence & $\begin{array}{l}\text { Significance } \\
\mathrm{P} \text { value }\end{array}$ & \\
\hline 1 & Cold hands & + & 0.207 & - \\
\hline 2 & Feeling cold & + & 0.001 & - \\
\hline 3 & $\begin{array}{l}\text { Low blood } \\
\text { pressure }\end{array}$ & + & 0.144 & - \\
\hline 4 & Dizziness & + & 0.695 & - \\
\hline 5 & Sleep onset & + & 0.218 & - \\
\hline 6 & Thirst & + & 0.470 & - \\
\hline 7 & Headache & + & 0.008 & - \\
\hline 9 & Drug sensitivity & + & 0.001 & - \\
\hline 10 & Pain & + & 0.219 & - \\
\hline 11 & Smell perception & + & 0.001 & - \\
\hline 15 & Skin blotches & + & 0.802 & - \\
\hline 8 & $\begin{array}{l}\text { Accompanying } \\
\text { symptoms }\end{array}$ & $=$ & 0.906 & $=$ \\
\hline 12 & $\begin{array}{l}\text { Low body weight } \\
\text { in early adulthood }\end{array}$ & - & 0.001 & + \\
\hline 13 & Perfectionism & - & 0.647 & + \\
\hline 14 & Tinnitus & $=$ & 0.951 & $=$ \\
\hline & $\Sigma$ criteria & $\begin{array}{c}11+ \\
2= \\
2-\end{array}$ & 5 significant & $\begin{array}{l}2+ \\
2= \\
11-\end{array}$ \\
\hline
\end{tabular}

The level of significance is noted. $P$ values below 0.05 are considered statistically significant and marked in red colour (symptoms $2,7,9,11$ and 12 ). Eleven symptoms united within the green-marked cluster demonstrate the prevalence increased in BC. The prevalence of four symptoms united within the yellow-marked cluster is either similar or decreased in BC

First of all, it is a systemic multi-contextual consideration of individual parameters. Just an example: since years, headache is a strongly disputed symptom regarding its breast cancer relevance. So far, in general, the dedicated studies have consider unilaterally the hormonal aspects of headache concluding that falling oestrogen levels which causes migraine are associated with a decreased risk of breast cancer, particularly amongst $\mathrm{ER}+\mathrm{PR}+$ ductal and lobular carcinomas [34, 35]. In contrast, results presented here demonstrate significantly higher prevalence $(P=0.008)$ of headache in the postmenopausal breast cancer patient group versus BC-free individuals. Certainly, whether prevalent or not, headache/migraine attacks is an indicator for severe pathological events which should be deeply analysed in a multi-parametric context. This is exactly what our current study did demonstrating that besides the prevalent headache, postmenopausal breast cancer patients investigated 
demonstrate a pronounced vascular dysregulation and consequently systemic hypoxic effects linked to the cardiovascular component (symptoms 1 "cold hands" and 2 "feeling cold"), altered sense regulation (symptom 11 "smell perception") and potential body dehydration (symptom 6 "do not feel thirsty and drink too little"). All of them are highly relevant for bothbreast cancer progression and headache.

\section{New interpretation of the "Seed and Soil" theory of metastasis in breast cancer}

Another conceptual novelty presented here is a new interpretation of the "Seed and Soil" theory of metastasis in breast cancer. It is important to emphasise that the responses given towards individual questions (see Fig. 1) refer to the health condition and behaviour of the patients considered in a longterm manner but not restricted to the period of time dedicated to the treatment of breast cancer and metastatic disease. Consequently, the results clearly support the hypothesis presented $[4,5]$ proposing that a strong epi/genetic predisposition of individuals at risk to form the systemic hypoxic premetastatic niches can be established a long time before the breast malignancy is clinically manifested. FS phenotype acts over several life decades contributing to pronounced vascular dysregulation and systemic hypoxic effects which, in turn, create the fertile microenvironment ("soil") in distant organs for the circulating tumour cells (CTC, "seeds") once they appear in the blood stream. This new concept explains well why and how "metastatic inefficiency" [36] may turn into aggressive metastatic disease. It is known that in manifested oncologic diseases, less than $1 \%$ of all disseminated and circulated tumour cells have a potential to form secondary and distanced tumours (metastatic diseases) - the phenomenon known as the metastatic inefficiency [36]. However, in case of the chronic systemic hypoxia, fertile microenvironment (soil) is highly supportive for both the initial tumour development in the breast tissue and aggressive metastatic disease via CTC (seeds) domesticated and progressing in distant organs which are systemically affected by hypoxic effects as well [3, 5]. In the new concept, the pre-metastatic niches (soil) are created by a systemic hypoxia a long time before the breast malignancy is clinically manifested.

\section{Study limitation}

The main limitation of the presented study is a relatively low number of the interviewed patients that hindered more precise patient stratification into corresponding subgroups towards disease-relevant parameters such as collateral pathologies and detailed characterisation of the metastatic disease diagnosed in a certain portion of the $\mathrm{BC}$ patients investigated, amongst others. This issue is considered for designing the follow-up projects.

\section{Conclusion and outlook}

Current multi-centred study highlights new complex mechanisms of the development and progression of the postmenopausal breast cancer. Innovative concepts are presented which argue for more effective predictive and preventive approaches being well justified in view of the clusters of the Flammer syndrome-symptoms analysed here and demonstrated as highly prevalent in the postmenopausal breast cancer versus $\mathrm{BC}$-free individuals. Regarding the next steps, we propose to perform the dedicated large-scale studies to validate the results introduced by this pioneer multi-centred pilot project. Followup studies may consider to stratify the patient subgroups utilising individual molecular biological profiles and complementary questionnaires related to the known breast cancer risk factors. Family doctors (GPs) should be obligatory involved in the follow-up studies for the educational purposes, creation and application of innovative screening programmes utilising the knowledge collected in the current project.

$B C$ breast cancer, $B M I$ body mass index, $C T C$ circulating tumour cells, FIA fibro-adenoma, FS Flammer syndrome, $G P s$ general practitioners (family doctors).

Acknowledgements The authors thank Prof. Dr. Josef Flammer, University of Basel, for his valuable recommendations during the preparation and performance of the actual multi-centred project.

Authors' contributions Olga Golubnitschaja is the project coordinator who has created the main scientific ideas and hypotheses presented in the manuscript; she has drafted the manuscript. Ivica Smokovski has coordinated the research, patient recruitment and data analysis performed in the Republic of Macedonia. Milan Risteski has performed the recruitment of all postmenopausal breast cancer patients and interviewed these patients in the Republic of Macedonia. Pavol Zubor has coordinated the research, patient recruitment and data analysis performed in Slovakia, analysed the corresponding patient data-base, selected breast cancer-free individuals for the reference group, and provided the final data from interviewing this group. Jiri Polivka Jr. has performed complete statistical analysis. Vincenzo Costigliola has contributed with his expertise in the European standards for primary care. Katarzyna Konieczka has contributed by the expertise in the Flammer syndrome. All the authors have read and approved the final manuscript.

Compliance with ethical standards All procedures performed in the current study involving human participants were in accordance with the ethical standards of the institutional and/or national research committee and with the 1964 Helsinki declaration and its later amendments or comparable ethical standards.

Competing interests The authors declare that they have no competing interests.

Funding This multi-centred study has been supported by the following organisations: European Association for Predictive, Preventive and Personalised Medicine, EPMA, Brussels, Belgium; Schwickert Foundation, Switzerland; and the National Sustainability Program I (NPU I) Nr. LO1503, Ministry of Education Youth and Sports, Czech Republic and MH CZ-DRO (Faculty Hospital in Plzen-FNPl, 00669806). 


\section{References}

1. Golubnitschaja O, Debald M, Yeghiazaryan K, Kuhn W, Pešta M, Costigliola V, Grech G. Breast cancer epidemic in the early 21 st century: evaluation of risk factors, cumulative questionnaires and recommendations for preventive measures. Tumor Biol. 2016;37(10):12941-57. doi:10.1007/s13277-016-5168-x.

2. Arnold M, Karim-Kos HE, Coebergh JW, Byrnes G, Antilla A, Ferlay J, Renehan AG, Forman D, Soerjomataram I. Recent trends in incidence of five common cancers in 26 European countries since 1988: analysis of the European cancer observatory. Eur J Cancer. 2015;51(9):1164-87. doi:10.1016/j.ejca.2013.09.002.

3. Golubnitschaja O. Feeling cold and other underestimated symptoms in breast cancer: anecdotes or individual profiles for advanced patient stratification? EPMA J 2017; 8(1):17-22. doi:10.1007/ s13167-017-0086-6.

4. Zubor P, Gondova A, Polivka J Jr, Kasajova P, Konieczka K, Danko J, Golubnitschaja O. Breast cancer and Flammer syndrome: any symptoms in common for prediction, prevention and personalised medical approach? EPMA J. 2017; doi:10.1007/s13167-017-00893.

5. Bubnov R, Polivka J Jr, Zubor P, Koniczka K, Golubnitschaja O. "Pre-metastatic niches" in breast cancer: are they created by or prior to the tumour onset? "Flammer syndrome" relevance to address the question. EPMA J. 2017; doi:10.1007/s13167-017-0092-8.

6. Kokolus K, Hing CC, Repasky EA. Feeling too hot or cold after breast cancer: is it just a nuisance or a potentially important prognostic factor? Int J Hyperth. 2010;26(7):662-80. doi:10.3109/ 02656736.2010 .507235 .

7. Daniels LB, Maisel AS. Cardiovascular biomarkers and sex: the case for women. Nat Rev Cardiol. 2015;12(10):588-96. doi:10. 1038/nrcardio.2015.105.

8. Golubnitschaja O, Debald M, Kuhn W, Yeghiazaryan K, Bubnov RV, Goncharenko VM, Lushchyk U, Grech G, Konieczka K. Flammer syndrome and potential formation of pre-metastatic niches: a multi-centred study on phenotyping, patient stratification, prediction and potential prevention of aggressive breast cancer and metastatic disease. EPMA J. 2016;7(Suppl 1):9,A25. doi:10.1186/ s13167-016-0054-6.

9. Cox TR, Rumney RM, Schoof EM, Perryman L, Hoye AM, Agrawal A, et al. The hypoxic cancer secretome induces premetastatic bone lesions through lysyl oxidase. Nature. 2015;522: 106-10. doi:10.1038/nature14492.

10. Vanharanta S. A hypoxic ticket to the bone metastatic niche. Breast Cancer Res. 2015;17(1):122. doi:10.1186/s13058-015-0635-7.

11. Konieczka K, Ritch R, Traverso CE, Kim DM, Kook MS, Gallino A, Golubnitschaja O, Erb C, Reitsamer HA, Kida T, Kurysheva N, Yao K. Flammer syndrome. EPMA J. 2014;5(1):11. doi:10.1186/ 1878-5085-5-11.

12. Yeghiazaryan K, Flammer J, Orgül S, Wunderlich K, Golubnitschaja O. Vasospastic individuals demonstrate significant similarity to glaucoma patients as revealed by gene expression profiling in circulating leukocytes. Mol Vis. 2009;15:2339-48.

13. Flammer J, Konieczka K, Flammer AJ. The primary vascular dysregulation syndrome: implications for eye diseases. EPMA J. 2013;4(1):14. doi:10.1186/1878-5085-4-14.

14. Yeghiazaryan K, Flammer J, Golubnitschaja O. Predictive molecular profiling in blood of healthy vasospastic individuals: clue to targeted prevention as personalised medicine to effective costs. EPMA J. 2010;1(2):263-72. doi:10.1007/s13167-010-0032-3.

15. Golubnitschaja O, Yeghiazaryan K, Flammer J. Key molecular pathways affected by glaucoma pathology: is predictive diagnosis possible? EPMA J. 2010;1(2):237-44. doi:10.1007/s13167-0100031-4.
16. Golubnitschaja O, Yeghiazaryan K, Costigliola V, Trog D, Braun M, Debald M, Kuhn W, Schild HH. Risk assessment, disease prevention and personalised treatments in breast cancer: is clinically qualified integrative approach in the horizon? EPMA J. 2013;4(1):6. doi:10.1186/1878-5085-4-6.

17. Konieczka K, Choi HJ, Koch S, Schoetzau A, Küenzi D, Kim DM. Frequency of symptoms and signs of primary vascular dysregulation in Swiss and Korean populations. Klin Monatsbl Augenheilkd. 2014;231(4):344-7. doi:10.1055/s-0034-1368239.

18. Konieczka K, Fränkl S. Primäre vaskuläre Dysregulation und Glaukom (Primary vascular dysregulation and glaucoma). Z prakt Augenheilkd. 2013;34:207-15.

19. Konieczka K, Koch S, Binggeli T, Schoetzau A, Kesselring J. Multiple sclerosis and primary vascular dysregulation (Flammer syndrome). EPMA J. 2016;7:13. doi:10.1186/ s13167-016-0062-6.

20. Konieczka K, Koch S, Schoetzau A, Todorova MG. Increased prevalence of Flammer syndrome in patients with retinitis Pigmentosa. Klin Monatsbl Augenheilkd. 2016;233(4):448-52. doi:10.1055/s0041-111802.

21. Konieczka K, Todorova MG, Chackathayil TN, Henrich PB. Cilioretinal artery occlusion in a young patient with flammer syndrome and increased retinal venous pressure. Klin Monatsbl Augenheilkd. 2015;232(4):576-8. doi:10.1055/s-0035-1545774.

22. Konieczka K, Flammer J, Sternbuch J, Binggeli T, Fraenkl S. Leber's hereditary optic neuropathy, normal tension glaucoma, and Flammer syndrome: long term follow-up of a patient. Klin Monatsbl Augenheilkd. 2017; doi:10.1055/s-0042-119564.

23. Health Consumer Powerhouse. Eurohealth Consumer Index Report, 2014. Taby, Sweden: Health Consumer Powerhouse. http://www.healthpowerhouse.com/files/EHCI_2014/EHCI 2014 report.pdf. Accessed on 22 Jan 2017.

24. Smokovski I, Milenkovic T, Trapp C, Mitov A. Diabetes Care in Republic of Macedonia: challenges and opportunities. Annals of Global Health. 2015;81(6):792-802. doi:10.1016/j.aogh.2015.12. 017.

25. Ministry of Health of Republic of Macedonia. National guidelines for medical care of breast cancer, 2015. http://zdravstvo.gov.mk/ wp-content/uploads/2015/08/Rak-na-dojka.pdf. Accessed on 22 Jan 2017.

26. Gershan V, Antevska-Grujoska S. Performance of mammography equipment in the Macedonian breast screening campaign 2008/2009. Radiat Prot Dosim. 2011;147(1-2):187-91. doi:10. 1093/rpd/ncr290.

27. Gjorgov NA. Breast cancer risk assessments to barrier contraception exposure. A new approach. Prilozi. 2009;30(1):217-32.

28. Ogden CL, Carroll MD, Kit BK, Flegal KM. Prevalence of childhood and adult obesity in the United States, 2011-2012. JAMA. 2014;311(8):806-14. doi:10.1001/jama.2014.732.

29. Overweight and obesity - BMI statistics [database on the Internet]. Eurostat. http://ec.europa.eu/eurostat/statistics-explained/index. php/Overweight_and_obesity_-_BMI_statistics Accessed on 28 March 2017.

30. Arnold M, Freisling H, Stolzenberg-Solomon R, Kee F, O'Doherty MG, Ordóñez-Mena JM, Wilsgaard T, May AM, Bueno-de-Mesquita HB, Tjønneland A, Orfanos P, Trichopoulou A, Boffetta P, Bray F, Jenab M, Soerjomataram I, CHANCES consortium. Overweight duration in older adults and cancer risk: a study of cohorts in Europe and the United States. Eur J Epidemiol. 2016;31(9):893-904. doi:10.1007/ s10654-016-0169-z.

31. Horn-Ross PL, Canchola AJ, Bernstein L, Neuhausen SL, Nelson DO, Reynolds P. Lifetime body size and estrogen-receptor-positive breast cancer risk in the California teachers study cohort. Breast Cancer Res. 2016;18(1):132. doi:10.1186/s13058-016-0790-5. 
32. Rosner B, Eliassen AH, Toriola AT, Chen WY, Hankinson SE, Willett WC, Berkey CS, Colditz GA. Weight and weight changes in early adulthood and later breast cancer risk. Int $\mathrm{J}$ Cancer. 2017;140(9):2003-14. doi:10.1002/ijc.30627.

33. Cebioglu M, Schild HH, Golubnitschaja O. Cancer predisposition in diabetics: risk factors considered for predictive diagnostics and targeted preventive measures. EPMA J. 2010;1(1):130-7. doi:10. 1007/s13167-010-0015-4.

34. Mathes RW, Malone KE, Daling JR, Davis S, Lucas SM, Porter PL, Li CI. Migraine in postmenopausal women and the risk of invasive breast cancer. Cancer Epidemiol Biomark Prev. 2008;17(11):311622. doi:10.1158/1055-9965.EPI-08-0527.

35. Li CI, Mathes RW, Bluhm EC, Caan B, Cavanagh MF, Chlebowski RT, Michael Y, O'Sullivan MJ, Stefanick ML, Prentice R. Migraine history and breast cancer risk among postmenopausal women. J Clin Oncol. 2010;28(6):1005-10. doi:10.1200/JCO.2009.25.0423.

36. Redig AJ, McAllister SS. Breast cancer as a systemic disease: a view of metastasis. J Intern Med. 2013;274(2):113-26. doi:10. 1111/joim.12084. 